\title{
Torulene and torularhodin: "new" fungal carotenoids for industry?
}

\author{
Anna M. Kot ${ }^{1 *}$, Stanisław Błażejak ${ }^{1}$, Iwona Gientka ${ }^{1}$, Marek Kieliszek ${ }^{1}$ and Joanna Bryś ${ }^{2}$
}

\begin{abstract}
Torulene and torularhodin represent the group of carotenoids and are synthesized by yeasts and fungi. The most important producers of these two compounds include yeasts of Rhodotorula and Sporobolomyces genera. The first reports confirming the presence of torulene and torularhodin in the cells of microorganisms date to the 1930s and 1940s; however, only in the past few years, the number of works describing the properties of these compounds increased. These compounds have strong anti-oxidative and anti-microbial properties, and thus may be successfully used as food, feedstock, and cosmetics additives. In addition, tests performed on rats and mice showed that both torulene and torularhodin have anti-cancerous properties. In order to commercialize the production of these two carotenoids, it is necessary to obtain highly efficient yeast strains, for example, via mutagenization and optimization of cultivation conditions. Further studies on the activity of torulene and torularhodin on the human body are also needed.
\end{abstract}

Keywords: Microbial carotenoids, Yeast, Rhodotorula, Sporobolomyces, Dyes

\section{Background}

Carotenoids are a group of compounds commonly present in nature. They are characterized by a yellow, orange, or red color and occur naturally in fruits, vegetables, algae, fish, eggs, and oil [1]. Nearly 750 carotenoids have been identified, including 50 found in food consumed by humans [2]. These compounds are the main source of vitamin $\mathrm{A}$ in the human diet, and they have health-promoting properties. Carotenoids reinforce the immune system of the body, accelerate the healing of wounds [3], and counteract eye conditions, such as cataracts [4] or age-related macular degeneration [5]. Carotenoid supplements are commonly used as agents protecting the skin against harmful ultraviolet radiation [6]. Carotenoids may also be used in cancer prevention owing to their anti-oxidative properties [7]. The human body cannot biosynthesize these compounds, thus they have to be supplemented in food. Carotenoids are widely used in the industry, i.e., as additives to food, diet supplements,

\footnotetext{
*Correspondence: anna_kot@sggw.pl

${ }^{1}$ Department of Biotechnology, Microbiology and Food Evaluation,

Faculty of Food Sciences, Warsaw University of Life Sciences,

Nowoursynowska 159C, 02-776 Warsaw, Poland

Full list of author information is available at the end of the article
}

and cosmetics. They are also an important ingredient of feedstock for poultry, fish, and mollusks. Currently, the greatest industrial importance is attached to $\beta$-carotene, astaxanthin, lutein, zeaxanthin, and canthaxanthin [8]. Because of their valuable properties, interest in other carotenoids has also increased recently. Such compounds include torulene and torularhodin. Their structure, properties, and potential industrial applications are described in this work. In addition, their sources, biosynthetic pathway, methods of extraction and analysis, and a recommended production method are presented.

\section{Structure and sources of torulene and torularhodin} Carotenoids are organic compounds and belong to 40-carbon terpenoids. The structure of the isoprene chain allowed to separate two groups of these compounds, and the presence of oxygen in the molecule provides the dividing criterion. Carotenes include only carbon and hydrogen atoms in their molecules, whereas xanthophylls have at least one additional oxygen atom in the molecule [9]. It is an element of a carboxy, hydroxy, carbonyl, or hydroxymethyl group. The presence of such functional groups renders xanthophylls more polar than carotenes [10]. Carotenes include, for instance, 
$\beta$-carotene and torulene, whereas xanthophylls include astaxanthin and canthaxanthin [9]. Due to the presence of a carboxy group in the torularhodin molecule, this compound may be classified as one of the xanthophylls.

Torulene $\quad\left(\mathrm{C}_{40} \mathrm{H}_{54}, \quad 3^{\prime}, 4^{\prime}\right.$-didehydro- $\beta, \psi$-carotene, Fig. 1$)$ and torularhodin $\left(\mathrm{C}_{40} \mathrm{H}_{52} \mathrm{O}_{2}, 3^{\prime}, 4^{\prime}\right.$-didehydro- $\beta, \psi$ caroten-16'-oic acid, Fig. 2) have one $\beta$-ionone ring connected to a polyene chain [11]. Due to the presence of thirteen double bonds, torulene and torularhodin have strong anti-oxidative properties [12-14]. It has been reported [15] that maximum absorption for torulene is observed at 460, 484 and $518 \mathrm{~nm}$ in petroleum ether. Torularhodin absorbed maximally at 465, 492 and $523 \mathrm{~nm}$ in petroleum ether. Depending on their concentration, they have a rosy-red color [16].

The first literature reports confirming the presence of torularhodin were released in the 1930s and were related to dyes extracted from biomass of yeasts of the Rhodotorula genus [18]. In 1946, Bonner et al. [19] found torulene in the cells of Rhodotorula rubra yeasts. Since then, the presence of torulene and torularhodin in the cells of yeast and fungi has been described; however, only the last decade observed an increase in the number of studies related to possibilities of synthesis of these compounds [15].

Torulene is synthesized by fungi of the genera Cystofilobasidium [11], Dioszegia [20, 21], Neurospora [22], Rhodotorula [23], Rhodosporidium [24], Sporidiobolus $[25,26]$, and Sporobolomyces [27-29]. Torularhodin is synthesized by fungi of the genera Cystofilobasidium [11], Rhodotorula [30, 31], Rhodosporidium [32], Sporidiobolus [33] and Sporobolomyces [27-29, 34]. Although these genera include a large number of species, only a few of these can accumulate significant amounts of these carotenoids. Cystofilobasidium infirmominiatum and
Cystofilobasidium capitatum are included in the class of Tremellomycetes, Neurospora crassa is included in the class of Sordariomycetes, while Rhodotorula glutinis, Rhodotorula mucilaginosa (syn. R. rubra), Rhodosporidium babjevae, Rhodosporidium toruloides Rhodotorula graminis, Sporidiobolus pararoseus, Sporidiobolus johnsonii Sporobolomyces ruberrimus, and Sporobolomyces salmonicolor are included in the class of Microbotryomycetes [35].

Due to the efficiency of biosynthesis, the most important producers of these two compounds include yeasts of Rhodotorula, Sporidiobolus and Sporobolomyces genera. Levels of torulene and torularhodin contents in the cellular biomass of various yeast strains are presented in Table 1.

\section{Role of carotenoids in yeast cells}

In microorganisms different functions have been attributed to carotenoids. The primary role of these compounds is protection against the negative influence of reactive forms of oxygen [11] and radiation [30]. Sakaki et al. [13] showed that torularhodin from $R$. glutinis had greater scavenging activity toward peroxyl radicals and inhibits degradation by singlet oxygen more effectively than $\beta$-carotene. In another study [12], torularhodin was shown to inhibit peroxidation of lipids, and its inhibitory effect was stronger than that of $\alpha$-tocopherol at the concentration of $1 \mu \mathrm{M}$. Moline et al. [49] tested the photoprotective role of carotenoids in S. ruberrimus and C. capitatum yeast. Radiation at the wavelengths 320 $400 \mathrm{~nm}$ (UV-A) causes only indirect damage to DNA, proteins, and lipids [30], while UV-B radiation (280$320 \mathrm{~nm}$ ) causes damage to DNA by generating two types of mutagenic lesions. To determine the photoprotective<smiles>CC(C)=C/C=C/C(C)=C/C=C/C(C)=C/C=C/C(C)=C/C=C/C=C(C)/C=C/C=C(C)/C=C/C1=C(C)CCCC1(C)C</smiles>

Fig. 1 Structural formula of torulene [17]<smiles>CC1=C(/C=C/C(C)=C/C=C/C(C)=C/C=C/C=C(C)/C=C/C=C(C)/C=C/C=C(C)/C=C/C=C(\C)C(=O)O)C(C)(C)CCC1</smiles>

Fig. 2 Structural formula of torularhodin [17] 
Table 1 Yield of torulene and torularhodin [mg/ $\mathrm{Lr} \mathbf{~ m g / 1 0 0 ~} \mathrm{g}_{\text {d.w.] }}$ ] biosynthesis by various yeast strains

\begin{tabular}{|c|c|c|c|c|}
\hline Microorganism & Cultivation medium/conditions & Torulene & Torularhodin & References \\
\hline \multicolumn{5}{|l|}{$\mathrm{mg} / 100 \mathrm{~g}_{\mathrm{d} . \mathrm{w}}}$. \\
\hline Rhodotorula glutinis mutant TL/21 & Addition of $0.01 \mathrm{mM}$ bromothymol blue & - & 4.9 & {$[36]$} \\
\hline Rhodotorula glutinis wild strain & Cultivation with white light irradiation & 32.2 & 14.2 & {$[31]$} \\
\hline \multirow[t]{2}{*}{ Rhodotorula glutinis DBVPG 3853} & Grape must concentrate & 8.51 & 72.13 & {$[23]$} \\
\hline & Soy flour extract & 9.63 & 70.84 & \\
\hline $\begin{array}{l}\text { Mixed culture } \\
\text { Rhodotorula rubra GED5 and Kluyveromyces lactis } \\
\text { MP11 }\end{array}$ & Whey & 2.69 & 22.23 & {$[37]$} \\
\hline \multirow[t]{4}{*}{ Rhodotorula mucilaginosa F-1 } & $25^{\circ} \mathrm{C}$ & 15.46 & 7.47 & {$[38]$} \\
\hline & $31{ }^{\circ} \mathrm{C}$ & 8.79 & 17.72 & \\
\hline & Molasses & 18.13 & 2.34 & \\
\hline & Ketchup production waste & 21.45 & 4.67 & \\
\hline Sporobolomyces salmonicolor $\mathrm{AL}_{1}$ & Saccharose & 27.37 & 45.83 & [29] \\
\hline Sporidiobolus pararoseus CCTCC M 2010326 & Fed-batch cultivation & 18.99 & - & [39] \\
\hline Sporidiobolus johnsonii DBVPG 7467 & Glucose & 0.77 & 4.12 & {$[40]$} \\
\hline Rhodotorula graminis DBVPG 7021 & Glucose & 18.23 & 9.31 & {$[41]$} \\
\hline \multicolumn{5}{|l|}{$\mathrm{mg} / \mathrm{L}$} \\
\hline Rhodotorula sp. KF-104 & YG medium & 1.74 & 1.92 & {$[42]$} \\
\hline Rhodotorula glutinis mutant 32 & Glucose & 5 & 3 & {$[43]$} \\
\hline Rhodotorula glutinis var. glutinis & Wort & 0.53 & 0.16 & {$[44]$} \\
\hline \multirow[t]{3}{*}{ Rhodotorula rubra ICCF 209} & Glucose $+0.1 \%$ oleic acid & - & 0.31 & {$[45]$} \\
\hline & MS3 medium & - & 0.71 & \\
\hline & Fructose & - & 0.40 & \\
\hline Rhodotorula rubra GED8 & Glucose & 0.87 & 1.22 & {$[46]$} \\
\hline \multirow[t]{2}{*}{ Rhodotorula rubra PTCC 5255} & Shaken culture & 5.09 & 7.80 & {$[47]$} \\
\hline & Cultivation in a biofermentor, irradiation at $1780 \mathrm{~lx}$ & 4.48 & 35.59 & \\
\hline \multirow[t]{4}{*}{ Rhodotorula mucilaginosa RCL-11 } & Control & $0.82 \mathrm{mg} / \mathrm{L}$ & $2.24 \mathrm{mg} / \mathrm{L}$ & [48] \\
\hline & $+\mathrm{CuSO}_{4}$ & $2.33 \mathrm{mg} / \mathrm{L}$ & $5.37 \mathrm{mg} / \mathrm{L}$ & \\
\hline & $+\mathrm{H}_{2} \mathrm{O}_{2}$ & $8.21 \mathrm{mg} / \mathrm{L}$ & $5.22 \mathrm{mg} / \mathrm{L}$ & \\
\hline & $\begin{array}{l}+\mathrm{CuSO}_{4} \\
+\mathrm{H}_{2} \mathrm{O}_{2}\end{array}$ & $5.60 \mathrm{mg} / \mathrm{L}$ & $4.03 \mathrm{mg} / \mathrm{L}$ & \\
\hline Rhodotorula mucilaginosa 108 & YM medium & $0.31 \mathrm{mg} / \mathrm{L}$ & $0.065 \mathrm{mg} / \mathrm{L}$ & [15] \\
\hline Rhodotorula graminis 125 & & $0.19 \mathrm{mg} / \mathrm{L}$ & - & \\
\hline Sporobolomyces sp. & & $0.07 \mathrm{mg} / \mathrm{L}$ & $0.01 \mathrm{mg} / \mathrm{L}$ & \\
\hline Sporobolomyces ruberrimus $\mathrm{H} 110$ & Technical glycerin, pH 6.0 & - & $31.54 \mathrm{mg} / \mathrm{L}$ & {$[34]$} \\
\hline Sporobolomyces ruberrimus $\mathrm{H} 110$ & Raw glycerin & 70 mg/L & $350 \mathrm{mg} / \mathrm{L}$ & {$[27]$} \\
\hline
\end{tabular}

role of carotenoids, the authors used pigmented and naturally occurring albino strains of yeast. The tests showed that the pigmented strains were more tolerant to UV-B than the albino strains. In addition, a high content of carotenoids in yeast cells during the stationary growth phase enhanced survival [49]. In their next study [30], it was confirmed that accumulation of torularhodin constitutes an important mechanism that improves the resistance of yeasts to UV-B. It is probable that carotenoids can be associated with modification of membrane permeability and thus increased cellular resistance to oxidation and radiation [50].

\section{Torulene and torularhodin biosynthesis in yeast cells}

Biosynthesis of torulene and torularhodin in microorganism cells includes a range of enzymatic reactions. General pathways for carotenoid biosynthesis have been reviewed by Simpson et al. [51] and later by Goodwin [17]. Firstly, acetyl-CoA is converted to 3-hydroxy3-methylglutaryl-CoA in the reaction catalyzed by hydroxymethylglutaryl-CoA synthase [EC 2.3.3.10]. Then, 3-hydroxy-3-methylglutaryl-CoA is transformed to mevalonic acid by hydroxymethylglutaryl-CoA reductase [EC 1.1.1.88]. Mevalonic acid is transformed into 
isopentenyl pyrophosphate (IPP) in several reactions catalyzed by specific kinases [EC 2.7.1.36, EC 2.7.4.2] and diphosphomevalonate decarboxylase [EC 4.1.1.33]. Isopentenyl pyrophosphate is subsequently transformed into dimethylallyl pyrophosphate (DMAPP) via isomerization. The next step, an addition reaction of three IPP molecules, leads to the formation of geranylgeranyl pyrophosphate (GGPP). Condensation of two molecules of this compound leads to the formation of phytoene, and it is catalyzed by phytoene synthase [EC 2.5.1.32]. The next reactions are catalyzed by phytoene desaturase [EC 1.3.99.28-31]. This enzyme is involved in neurosporene formation and catalyzes up to three desaturation steps. Neurosporene may be transformed into lycopene or $\beta$-zeacarotene $[17,51,52]$. Lycopene cyclization or $\beta$-zeacarotene dehydrogenation leads to the formation of $\gamma$-carotene [52]. The $\gamma$-carotene molecule provides a precursor for the biosynthesis of $\beta$-carotene and torulene, whereas torularhodin is obtained in a further transformation of torulene, including hydroxylation and oxidation (Fig. 3) [53].

According to the study by Li et al. [26], torulene can also be produced from 3,4-dehydrolycopene. This compound is synthesized from lycopene by phytoene desaturase. The transformation from 3,4-didehydrolycopene to torulene is catalyzed by phytoene synthase/lycopene cyclase AL-2. This type of transformation occurs in $S$. pararoseus yeast. It is also known that 3,4-didehydrolycopene is the precursor of torulene in N. crassa.

\section{Use of molecular and -omics tools to characterize and improve carotenoid biosynthesis by red yeasts}

In recent years, the use of molecular and -omics tools in the characterization of red yeast has increased [55]. To date, whole genome sequences of some carotenogenic yeast have been identified, for example $R$. glutinis ATCC 204091 [56], $R$. graminis WP1 [57], $R$. mucilaginosa RIT389 [58] R. toruloides ATCC 10788 and ATCC 10657 [59], R. toruloides MTCC 457 [60], R. toruloides CECT1137 [61], and $R$. toruloides CGMCC 2.1609 [62]. Genome sequencing of $R$. toruloides NP11 has led to the identification of two genes that code carotenoid synthesis-related enzymes, phytoene synthase (PSY1) and phytoene dehydrogenase (CRTI) [63]. Gan et al. [58] identified genomic regions containing the key genes for carotenoid production in $R$. mucilaginosa. The genes coding for phytoene synthase $(c r t B)$, lycopene cyclase $(c r t Y)$, and phytoene desaturase ( $c r t I)$ were located in relatively close proximity to one another. Gene coding for the enzyme geranyl pyrophosphate synthase is located on separate contigs. Another study [64] identified a set of genes involved in different steps of carotenogenesis in $R$. mucilaginosa. It was shown that genes coding for 3-hydroxy-3-methylglutaryl-CoA reductase and mevalonate kinase are induced during exponential growth phase. This trend was not observed for phytoene synthase/lycopene cyclase and phytoene dehydrogenase encoding genes. It was also found that the transcript levels of genes coding for carotenoid dioxygenase, superoxide dismutase and catalase $\mathrm{A}$ increased during the accumulation of carotenoids. Li et al. [26] observed that expression of genes in S. pararoseus NGR encoding a phytoene desaturase ( $c r t I)$ and lycopene cyclase and phytoene synthase $(\mathrm{crtB})$ were 5.2- and 2.5-fold higher upon exposure to $\mathrm{NaCl}$. Under these conditions, the production of 3,4-didehydrolycopene increases, thus resulting in a subsequent increase in torulene and torularhodin bioproduction.

Genetic engineering tools also have the potential to increase the efficiency of carotenoid biosynthesis by yeast. Wang et al. [65] used chemical-physical mutagenesis for modification of a strain of the red yeast $R$. mucilaginosa $\mathrm{KC} 8$, which synthesized mainly $\beta$-carotene and torularhodin. After mutagenesis, $R$. mucilaginosa $\mathrm{K} 4$ synthesized $67 \%$ more carotenoids (14.47 $\mathrm{mg} / \mathrm{L})$ than parental strain $\mathrm{KC} 8(8.67 \mathrm{mg} / \mathrm{L})$. To further enhance carotenoid production, gene HMG1 encoding the 3-hydroxy-3-methylglutaryl coenzyme A (HMG-CoA) reductase was overexpressed in $R$. mucilaginosa K4. The carotenoid production of HMG1-gene-overexpression transformant $\mathrm{G} 1$ reached $16.98 \mathrm{mg} / \mathrm{L}$. In the next step, ketoconazole (ergosterol synthesis inhibitor) was added to the cultivation medium at a concentration of $28 \mathrm{mg} / \mathrm{L}$. The carotenoid production of transformant G1 reached $19.14 \mathrm{mg} / \mathrm{L}$, and this was $121 \%$ higher than in $R$. mucilaginosa KC8.

\section{Factors affecting the torulene and torularhodin biosynthesis in yeast cells}

The yield of carotenoid biosynthesis and the percentage levels of torulene and torularhodin do not have constant values. The efficiency of this process is primarily influenced by the composition of the medium and the cultivation parameters. The content of individual carotenoid fractions also depends to a large extent on the yeast strain (Table 1).

One of the most important factors that significantly regulates the process of carotenogenesis is the type and content of compounds that constitute sources of carbon and nitrogen. The optimal type of these compounds should be determined individually for each yeast strain [66-69]. Buzzini and Martini [23] cultivated R. glutinis yeasts in media containing various carbon sources. The highest total level of carotenoids $\left(915.4 \mu \mathrm{g} / \mathrm{g}_{\text {d.w. }}\right)$ was obtained in the biomass of yeasts from cultivation in a medium with concentrated grape must. In 


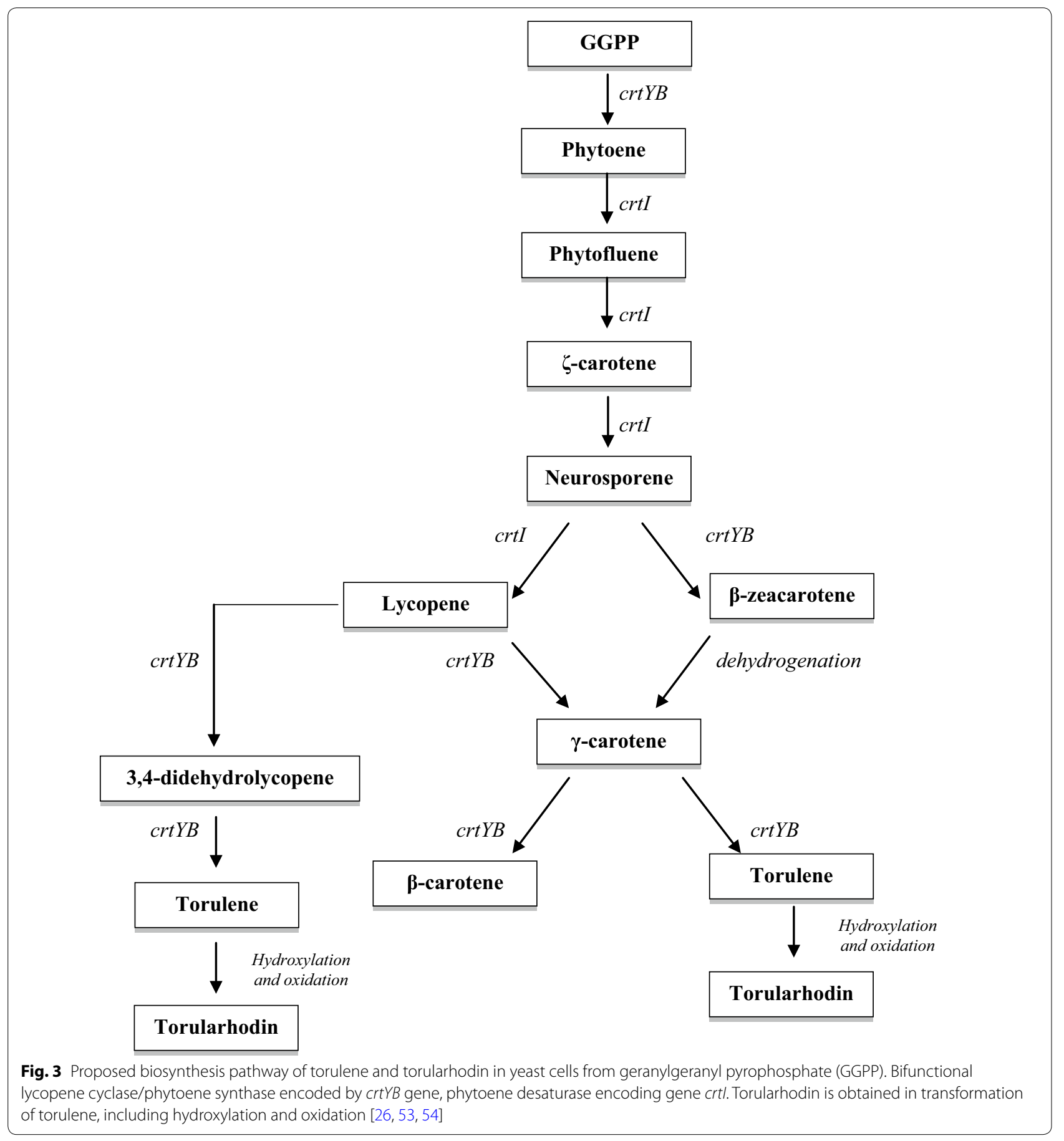

this case, the highest amount of torulene $\left(85.1 \mu \mathrm{g} / \mathrm{g}_{\mathrm{d} . \mathrm{w}}\right)$ and torularhodin $\left(721.3 \mu \mathrm{g} / \mathrm{g}_{\mathrm{d} w \mathrm{w}}\right)$ was also obtained, and their ratio reached 9.3:78.8. The remaining part included $\beta$-carotene (9.2\%). However, in the medium with glucose syrup, the yield of carotenoid was nearly fourfold less $\left(240.0 \mu \mathrm{g} / \mathrm{g}_{\mathrm{d} . w}\right)$, and the ratio of torulene and torularhodin was 10.8:85.0. Under these conditions, the $R$. glutinis yeast was unable to biosynthesize $\beta$-carotene.

The next required nutrient that must be present in the medium is nitrogen. El-Banna et al. [67] found that selection of the type of nitrogen compounds 
significantly influences the yields of torulene and torularhodin biosynthesized by $R$. glutinis yeasts. The highest yield of torulene $\left(243 \mu \mathrm{g} / \mathrm{g}_{\text {d.w. }}\right)$ was observed after cultivation in a medium with peptone. In these conditions yeast was unable to synthesize torularhodin. The highest level of this compound $\left(20.2 \mu \mathrm{g} / \mathrm{g}_{\text {d.w. }}\right)$ was obtained in the biomass of yeasts cultivated in a medium containing ammonium sulfate.

Selection of the appropriate concentrations of microelements in the cultivation medium is another factor required in order to achieve high yields of carotenoid biosynthesis [43]. The presence of some metal ions can stimulate or inhibit cellular enzymes participating in production of carotenoid compounds [70]. Experiments performed using $R$. graminis yeast also proved that the content of some trace elements in the cultivation medium influenced the profile of carotenoid. For example, the simultaneous presence of zinc and manganese ions in the medium completely inhibited torulene and torularhodin production [41].

Yeasts of Rhodotorula and Sporobolomyces genera are aerobic microorganisms, and thus adequate aeration is necessary in order to obtain high biosynthetic yields of torulene and torularhodin. Simova et al. [71] cultivated a mixture of $R$. rubra yeasts and Lactobacillus casei subsp. casei bacteria. The authors observed that the increase in aeration rate from $0.4-1.3$ to 1.6 $\mathrm{L} / \mathrm{L}$ min led to a decrease in the produced torularhodin from 44.0 to $29 \%$, whereas the levels of torulene remained relatively constant $(9.5-11.0 \%)$. The content of $\beta$-carotene increased, from 42.0 to $60.0 \%$.

Cultivation temperature is an important parameter influencing the amount of carotenoid compounds produced by yeasts. The influence of temperature is correlated to the activity of enzymes participating in the biosynthesis of carotenoids and in their regulation [52]. Temperature influences not only the general amount of produced carotenoids, but also the relative ratio of $\beta$-carotene, torulene, and torularhodin levels. Increased synthesis of $\beta$-carotene by yeast promotes a lower temperature. In the case of torulene and torularodine, the situation is the opposite. The increase in their production takes place at higher temperatures [51, 72]. It is probable that at low temperature enzymes involved in the biosynthesis of torulene are less active, and the content of $\beta$-carotene increases [73]. Frengova et al. [72] cultivated co-culture of R. rubra and Lactobacillus helveticus at 20 and $35{ }^{\circ} \mathrm{C}$. In the first case, $\beta$-carotene, torulene, and torularhodin content amounted to 19.0, 22.8 , and $56.0 \%$, respectively. At $35{ }^{\circ} \mathrm{C}$, total amount of $\beta$-carotene and torulene was low (9.6 and 9.0\%), while the content of torularhodin increased significantly (78.3\%).
The active acidity of the culture medium also significantly affects the yield and profile of carotenoids synthesized by microorganisms. Cheng and Yang [38] studied the influence of initial $\mathrm{pH}$ of the medium (from 4 to 7) on the content and profile of carotenoids synthesized by R. mucilaginosa $\mathrm{R}-1$ yeasts. The initial $\mathrm{pH}$ of the medium had the strongest influence on the content of $\beta$-carotene and torularhodin. After cultivation in a YM medium with the initial $\mathrm{pH}$ of 4.0 , torularhodin content was $20.1 \%$, which increased to $36.0 \%$ in a medium at $\mathrm{pH} 7.0$. A reverse trend was observed for $\beta$-carotene, its amount decreased under these conditions from 41.1 to $13.6 \%$.

Addition to the culture medium of some chemical compounds and modification of culture conditions may induce the process of carotenoid biosynthesis in yeast cells [70]. In order to cope with the harmful effects of stress, microorganisms have developed defensive reactions to quickly repair damage and further protect the cell. It has also been found [74] that yeasts subjected to a mild form of stress can after some time tolerate higher doses of a stress factor. Such environmental factors include irradiation, increased osmotic pressure, the presence of reactive oxygen species and also some organic solvents $[70,75,76]$.

Increasing the content of carotenoids during exposure to irradiation results from the higher expression of genes coding for the production of enzymes involved in the carotenoid biosynthetic pathway. This is a natural mechanism of cell response to adverse environmental conditions [70]. Sakaki et al. [31] determined the influence of white light on carotenoid biosynthesis by $R$. glutinis no. 21 yeasts. They concluded that irradiation of the cultivation intensified the production of all carotenoids, in particular of torularhodin. The amount of this compound showed an almost twofold increase, from 7.9 to $14.2 \mathrm{mg} / 100 \mathrm{~g}_{\text {d.w. }}$.

Addition of various chemicals, such as ethanol, methanol, isopropanol, or glycol to the cultivation medium may also influence the biosynthesis of torulene and torularhodin by yeasts. For example, supplementation of the cultivation medium with $2 \%$ ethanol stimulated the biosynthesis of $\beta$-carotene and torulene by $R$. glutinis yeasts, whereas torularhodin synthesis was limited under these conditions [73].

\section{Extraction and analysis of torulene and torularhodin}

Carotenoids present in yeast cells are accumulated mainly in lipid bodies, and thus an appropriate method of cell disintegration should be applied in order to ensure highly efficient extraction of these compounds. However, disintegration and extraction processes must also ensure the stability of carotenoids. Torulene and torularhodin 
are highly unstable compounds and should be protected from light, heat and oxygen. Carotenoids lose their color during exposure to oxidizing species. This process involves interruption of the conjugated double bonds [77].

Mechanical techniques such as high-pressure homogenization and ball mills are traditionally used for disintegration. However, because of the high costs and long performance time [78], disintegration methods using ultrasound, enzymatic preparations, chemicals such as dimethyl sulfoxide (DMSO), sodium carbonate and acids [79], as well as the use of liquid nitrogen [80] are growing increasingly popular.

Organic solvents such as acetone, petroleum ether, hexane, chloroform, ethanol, and methanol are commonly used in the extraction of carotenoids from microbial cells. These solvents are more often used as mixtures and display synergic activity, additionally damaging the cell wall, thus resulting in significantly increased yields of carotenoid extraction [78]. Park et al. [81] achieved the highest yield of carotenoid extraction from the biomass of $R$. glutinis KCTC 7989 yeasts using a mixture of dimethyl sulfoxide, petroleum ether, and acetone. A combination of these compounds is commonly used in the extraction of carotenoids from biomasses of yeasts synthesizing torulene and torularhodin [82-86]. Carotenoids may also be extracted from microbial cells using plant oils. Mihalcea et al. [77] used sunflower oil for this purpose. Biomass of $R$. rubra yeasts was initially subjected to high-pressure disintegration (five cycles, 15002000 bar). After this stage, the cells were suspended in $50 \mathrm{~mL}$ of sunflower oil and emulsified in a homogenizing device at 1500 bar. This treatment allowed a pink emulsion to be obtained, containing a water-based part and an oil-based part containing the carotenoids. Ungureanu et al. [87] proposed the use of centrifugal partition extraction (CPE) as a novel method for recovery of torularhodin from $R$. rubra cells. For extraction a mixture of hexane/water with acetone was used as the "bridge solvent". The compositions of the stationary phase and the mobile phase were $29 / 71 / 0$ and 2/62/36 (v/v/v), respectively, for hexane/acetone/water. The efficiency of the extraction increased with increased operating flow rate. The authors demonstrated that the extraction yield could reach $91 \%$ in a few minutes. The recovery of torularhodin reaches $294 \mu \mathrm{g} / \mathrm{L}$ of culture medium.

Subsequently, the extracted carotenoids should be subjected to separation and purification. Latha and Jeevaratanm [88] used column chromatography for separation of pigments of a crude extract from the yeast $R$. glutinis DFR-PDY. In these conditions, carotenoids were fractioned on magnesium oxide-Hyflo Super Cel by petroleum ether. The major red-colored fraction-torularhodin, was adsorbed on the column, while $\beta$-carotene and torulene were eluted by the petroleum ether, ethyl ether and methanol. Torularhodin was eluted with acetic acid-ethyl ether (1:10). Ungureanu and Ferdes [89] reported that extraction with alkaline methanol allows isolation of the torularhodin (acid structure) component from a carotenoid mixture. For the purification, Latha and Jeevaratanm [88] saponified fractions by adding potassium hydroxide-methyl alcohol solution, and next added petroleum ether to the mixture. This solvent was then dried over anhydrous sodium sulfate. For purification of torularhodin produced by S. ruberrimus H110, Razavi and Blanchard [90] used a perfusion chromatography work station. Torularhodin was eluted by applying a $150 \times 4.6 \mathrm{~mm}$, Symmetry C18 $(3.5 \mu \mathrm{m})$ column with an acetonitrile-methanol-dichloromethane mixture. After this process, solvents were evaporated and torularhodin was stored in a mixture of hexane and ethyl acetate, at $-18^{\circ} \mathrm{C}$.

Torulene and torularhodin concentrations can be determined based on the spectrometric recording of the extracts on a UV-Vis spectrophotometer [55, 89]. This method is simple, but accurate only when there is one compound in the sample [55]. Carotenoids have specific absorbance spectra, and during analysis of a mixture of these compounds, the absorbance may change depending on the wavelength applied [91].

A new method that allows the measurement of the total carotenoid content in yeast biomass in near real time is multi-parameter flow cytometry. The analysis is performed in vivo, immediately after sampling, which reduces degradation of the carotenoids [55]. Freitas et al. [92] used flow cytometry for determination of total carotenoid content in $R$. toruloides NCYC 921. This strain synthesizes mainly $\beta$-carotene, torulene and torularhodin. Based on the obtained results, the authors concluded that flow cytometry can be used in the optimization of yeast carotenoid production, from lab to pilot scales, but this technique gives information only on the total carotenoid content.

A more accurate method for carotenoid quantification involves the uses of reverse-phase high-performance liquid chromatography. This method allows the detection and quantification of the individual carotenoids in a mixture [55]. Currently, the most commonly used system includes a reverse phase system using $\mathrm{C}_{18}$ analytical columns [93]. Separation may be performed either by isocratic or a gradient elution, using both organic solvents and their mixtures with water. These compounds may be subsequently identified using spectrophotometric detectors, light-scattering detectors with evaporation, diodetype detectors, refractometric detectors (Table 2), or using mass spectrometry [27, 93]. Razavi and Blanchard 
Table 2 Chromatographic analysis methods used for torulene and torularhodin

\begin{tabular}{|c|c|c|c|c|}
\hline Mobile phase composition & Elution type & Analytic column type & Detector & Literature \\
\hline $\begin{array}{l}\text { Acetonitrile:isopropanol:ethyl acetate } \\
4: 4: 2(\mathrm{v} / \mathrm{v} / \mathrm{v})\end{array}$ & Isocratic & C18 (Restek Ultra type, Restek) & Evaporative light scattering detector & [94] \\
\hline $\begin{array}{l}\text { Acetonitrile:dichloromethane:methanol } \\
7: 2: 1(\mathrm{v} / \mathrm{v} / \mathrm{v})\end{array}$ & Isocratic & Spherisorb ODS2 (Alltech Associates) & Refractometer detector & [95] \\
\hline $\begin{array}{l}\text { Acetonitrile:tetrahydrofuran:water } \\
\text { 5:3:1 }(\mathrm{v} / \mathrm{v} / \mathrm{v})\end{array}$ & Isocratic & C18 ( $\mu$-Bondapak type, Waters) & UV/Vis detector; $501 \mathrm{~nm}$ & [91] \\
\hline $\begin{array}{l}\text { Methanol:acetonitrile } \\
9: 1(v / v / v)\end{array}$ & Isocratic & C18 (Novapak C type, Waters) & UVNis detector; $450 \mathrm{~nm}$ & [96] \\
\hline $\begin{array}{l}\text { Acetone:water } \\
\text { 95:5 (v/v) }\end{array}$ & Isocratic & RP-18 (LiChrospher 100 type, Merck) & UV/Vis detector; $450 \mathrm{~nm}$ & [97] \\
\hline $\begin{array}{l}\text { Acetonitrile:methanol:methylene chloride } \\
71: 22: 7(\mathrm{v} / \mathrm{v} / \mathrm{v})\end{array}$ & Isocratic & C18 (Waters type, Milford) & UVNis detector; 420-500 nm & [98] \\
\hline $\begin{array}{l}\text { A: acetone with a } 0.1 \% \text { addition of trifluoro- } \\
\text { acetic acid (TFA) } \\
\text { B: water with } 0.1 \% \text { TFA }\end{array}$ & Gradient & RP-18 (LiChrospher 100 type, Merck) & Diode-array detector & [27] \\
\hline $\begin{array}{l}\text { A: methanol: ethyl acetate 1:1 }(\mathrm{v} / \mathrm{v}) \text { with a } \\
0.05 \% \text { addition of triethylamine and } 0.1 \% \\
\text { BHT } \\
\text { B: acetonitrile with a } 0.05 \% \text { addition of trieth- } \\
\text { ylamine and } 0.1 \% \text { BHT }\end{array}$ & Gradient & C18 (Supelcosil type, Sigma-Aldrich) & UV/Vis detector; $450 \mathrm{~nm}$ & [85] \\
\hline $\begin{array}{l}\text { A: acetone } \\
\text { B: water }\end{array}$ & Gradient & C18 (Cosmosil type, Nacalai Tesque) & Diode-array detector & [99] \\
\hline
\end{tabular}

[90] determined that the limit of detection for torularhodin is estimated at $9 \mathrm{ng} / \mathrm{mL}$. For separated isometric forms of carotenoids it is necessary to used specific types of cinematographic columns. For example, Shi et al. [25] used an HPLC-DAD coupled with an atmospheric-pressure chemical ionization (APCI) MS method for identification of torulene cis/trans geometrical isomers isolated from $S$. pararoseus. The torulene fraction was prepared by column chromatography. For separation of torulene isomers, a YMC $\mathrm{C}_{30}$ column $(5 \mu \mathrm{m}, 250 \times 4.6 \mathrm{~mm})$ was used, together with a binary gradient mobile phase consisting of methanol-methyl tert-butyl ether-water, $(50: 47.5: 2.5, \mathrm{v} / \mathrm{v} / \mathrm{v})(\mathrm{A})$ and methanol-methyl tert-butyl ether-water, (8:90:2, v/v/v) (B). In these conditions, eight isomers of torulene, with a molar mass of $535 \mathrm{~g} / \mathrm{mol}$, were isolated: di-Z-Torulene (isomers 1 and 2), mono-ZTorulene (isomers 3-7) and All-E-Torulene. It is probable that, due to the presence of 13 double bonds, more torulene cis forms are formed.

\section{Suggested procedure for industrial production of torulene and torularhodin}

Torulene and torularhodin are not currently produced or used in industry; however, they have many potential applications thanks to their properties. A suggested production diagram for torulene and torularhodin using yeasts is presented in Fig. 4, prepared on the basis of information on carotenoids included in the literature [16, 78, 100-105]. Obtaining satisfactory production yields requires appropriate yeast strains characterized by intensive carotenoid synthesis to be selected, as well as optimal conditions and microbial cultivation parameters to be determined. After cultivation, the first stage of the process includes separation of yeast biomass from the post-culture medium, e.g., using centrifugation [106]. Thus, obtained yeast biomass may be subsequently dried or lyophilized [107], and the obtained product may be used as a valuable additive to feedstock for animals [53]. Separation of torulene and torularhodin from yeast cells requires an appropriate disintegration method, allowing efficient extraction of these dyes [78]. In the next stage, the extracted carotenoids dissolved in organic compounds may be subjected to individual operations such as concentration, filtration, and dehydration [108]. Next, it is necessary to evaporate the residues of organic solvents under reduced pressure, which guarantees stability of the dyes [103]. The evaporation residue may be subsequently dissolved in various edible oils, thus obtaining an oil enriched with a mixture of carotenoids [109] or crystallized in order to separate the mixture of dyes in its crystalline form [100]. In order to obtain the torulene and torularhodin fractions, it is necessary to separate the obtained carotenoid extract using chromatography, and the separated fractions may be subsequently crystallized [104] obtaining preparations of torulene and torularhodin. 


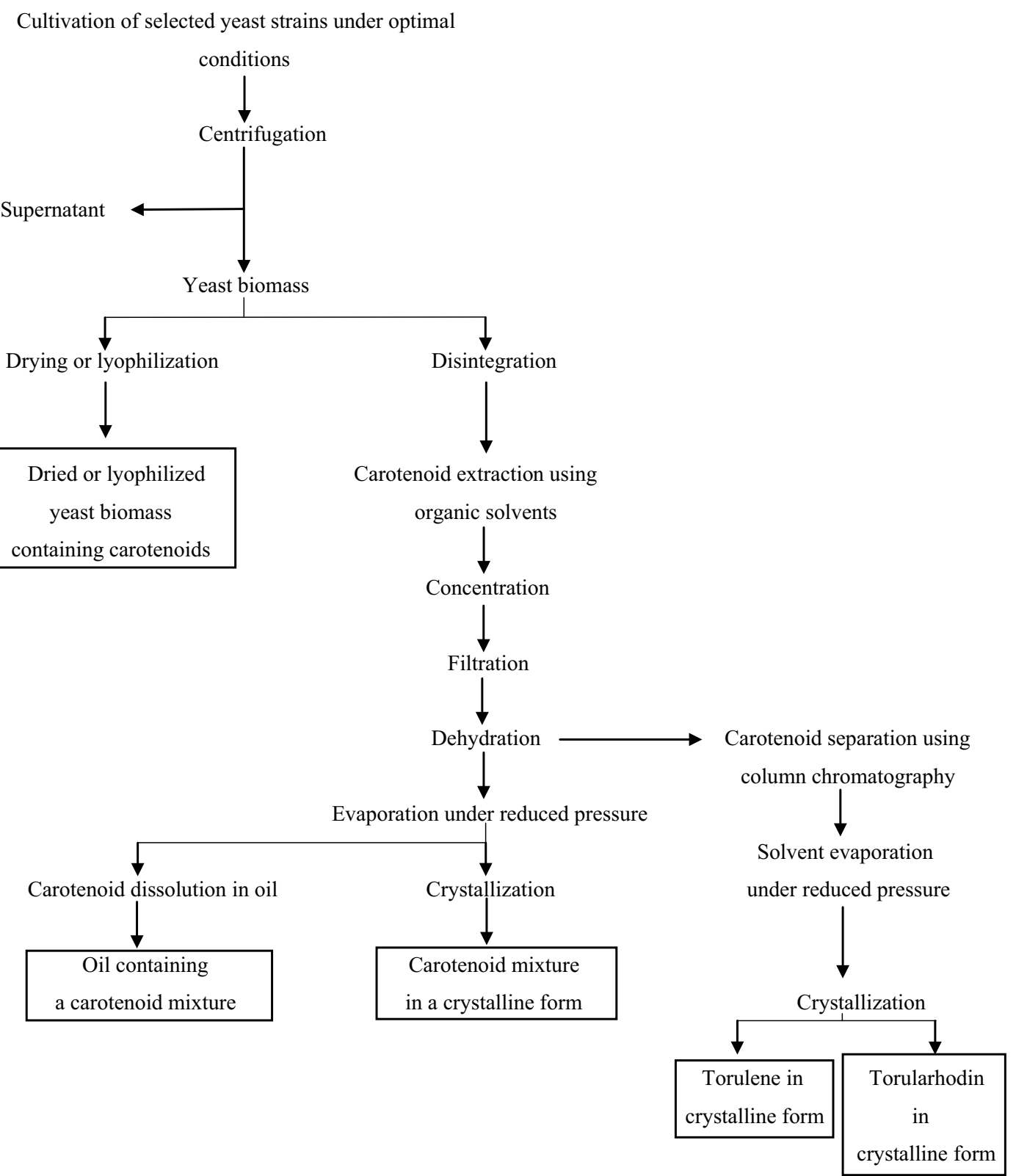

Fig. 4 Suggested diagram for the production of torulene and torularhodin using yeasts [prepared on the basis of works of 16, 78, 100-105]

\section{Properties and potential applications of torulene and torularhodin}

Torulene and torularhodin are absent in food, thus their influence on the human body has not been studied and described as yet. However, taking into account their chemical structure and properties, these compounds may probably be successfully used as food additives and additives in feedstock for animals, and in cosmetics [16] as well as ingredients in medicines [14]. Research on properties and potential use is presented below.

\section{Toxicity}

Latha and Jeevaratanm [110] studied the toxicity of carotenoids produced by $R$. glutinis DFR-PDY yeasts in rats. This strain synthesizes $\beta$-carotene, torulene, and torularhodin, as described by the authors in regard to their previous studies [88]. Over the course of 13 weeks, animals received a lower (100 $\mathrm{mg} / \mathrm{kg}$ of body mass) and a higher (300 mg/kg body mass) dose of carotenoids. The control group animals received only palm oil. A blood count examination did not indicate significant differences in the 
count of red blood cells, the hematocrit number, platelet count, mean corpuscular volume (MCV), or mean corpuscular hemoglobin concentration (MCHC), whereas the count of white blood cells was significantly lower only in males that received the higher dose of carotenoids. Urine parameters of experimental animals did not differ significantly in the control group and in the groups consuming the lower and the higher carotenoid doses. Histopathological examinations of lungs, liver, and kidneys did not show pathological changes in the tested rat groups. The authors concluded that carotenoids synthesized by the $R$. glutinis DFR-PDY yeasts may be used as food additives, which infer anti-oxidative properties in addition to their colorant role [110].

\section{Anti-cancer activity}

Another study [111] tested anti-cancer activity of carotenoids synthesized by $R$. glutinis NCIM 3353 yeasts in male Wistar race rats. Powdered biomass of $R$. glutinis yeasts containing torulene, torularhodin, and $\beta$-carotene in a 58:33:6 ratio was added to the feedstock. On the basis of the obtained results the authors concluded that carotenoids showed protective properties in preneoplastic changes of liver induced by dimethylnitrosamine. Du et al. [112] tested the anti-cancer activity of carotenoids in mice that orally received 9 or $18 \mathrm{mg} / \mathrm{kg} /$ day of torulene or torularhodin, respectively. After 2 weeks of supplementation, the mice were infected with hormone-independent PC-3 prostate cancer cells and the administration of carotenoids was continued. The animals were euthanized after 7 weeks and subjected to histopathological analysis. These examinations showed that both torulene and torularhodin significantly inhibited the development of prostate cancer in the studied mice. Diet supplementation with torulene and torularhodin at $18 \mathrm{mg} / \mathrm{kg}$ body mass resulted in a decrease in tumor volume from $248.13 \pm 28.74$ to $70.34 \pm 6.77$ and $60.53 \pm 6.78 \mathrm{~mm}^{3}$, respectively. This effect was related to apoptosis of cancer cells (reduction of Bcl-2 proteins) and amplified expression of the Bax protein and of caspase-3, -8, and -9. The next work [113] confirmed the anti-cancer properties of torulene using prostate cancer cells of the LNCaP line. Wu et al. [114] concluded that torularhodin shows neuroprotective activity against $\mathrm{H}_{2} \mathrm{O}_{2}$-induces oxidative injury, related to its strong antioxidative activity.

\section{Anti-oxidative properties}

Both torularhodin and torulene exhibit strong anti-oxidative properties. Dimitrova et al. [29] determined the anti-oxidative capacity (ORAC) of these two compounds using Trolox. Values of this indicator for torulene and torularhodin were 2.77 and 3.9, respectively, and were lower than anti-oxidative capacity determined for $\beta$-carotene (3.78). Other studies [18] noted that torularhodin neutralizes free radicals more efficiently than $\beta$-carotene. Oxidation reaction of 1,3-diphenylisobenzofuran (DPBF) was used for the purpose, with 3-(1,4-epidioxy-4-methyl-1,4-dihydro-1-naphthyl)propionic acid (EPA) as a source of singlet-state oxygen. Under such conditions, DPBF decomposed at a slower rate $(0.002 \mathrm{mM} / \mathrm{h})$ than in a sample using $\beta$-carotene $(0.013 \mathrm{mM} / \mathrm{h})$, which led to a conclusion that torularhodin neutralizes free radicals more efficiently than $\beta$-carotene. Ungureanu and Ferdes [14] determined anti-oxidative activity of methanolic torularhodin extracts using chemiluminescence. The studied extracts showed strong anti-oxidative activity. Torularhodin showed the activity of $96 \%$ directly after extraction, and this value decreased by 7 and $17 \%$, respectively, after 7 and 14 days. Anti-oxidative capacity was determined simultaneously using photochemiluminescence, and the value of this index was found to be $255.6 \mu \mathrm{g} / \mathrm{mL}$ of Trolox equivalents.

\section{Anti-microbial activity}

Carotenoids synthesized by yeasts of the Rhodotorula and Sporobolomyces genera show strong anti-microbial activity [14, 115-117]. Ungureanu and Ferdes [14] determined the anti-microbial activity of methanolic torularhodin extracts. The performed study led to the conclusion that torularhodin showed anti-bacterial and anti-fungal properties toward all tested strains. The growths of Fusarium oxysporum MUCL 791 and Aspergillus ochraceus molds and Candida utilis yeasts and Enterococcus faecalis ATCC 29212 bacteria was inhibited at a torularhodin concentration of $44.375 \mu \mathrm{g} / \mathrm{L}$. Escherichia coli K 12-MG1655 and Staphylococcus aureus ATCC 25923 bacteria were more susceptible to the activity of this compound, and the MIC value was $22.18 \mu \mathrm{g} / \mathrm{L}$. The strong anti-microbial properties of torularhodin may also be used in the production of implanted medical products. Although stringent sterile procedures are observed, peri-implantation infections interrupting the process of implant connection to the living tissue are still being diagnosed. Microorganisms may colonize surfaces of materials, devices, and medical implants, forming biofilms [118]. Ungureanu et al. [119] determined the properties of titanium implants coated with a torularhodin solution, with an additional layer of titanium dioxide used. Titanium implants were dipped in a torularhodin solution $(5 \mathrm{mg} / \mathrm{L})$ or in a 1:1 mixture of dopamine $\left(5 \times 10^{-3} \mathrm{M}\right)$ and torularhodin. Anti-microbial activity was tested on both Gram-negative (E. coli ATCC 8738, Pseudomonas aeruginosa ATCC 9027) and Gram-positive bacteria (S. aureus ATTC 25923, E. faecalis ATCC 29212, Bacillus 
subtilis ATCC 6633). Torularhodin effectively inhibited proliferation and adhesion of the studied bacterial strains, and the anti-microbial activity of films containing torularhodin and torularhodin with dopamine was higher than that of cefotaxime (III generation antibiotic) toward E. coli, S. aureus and B. subtilis bacteria. Moreover, titanium implants with an additional coating were characterized by good hemocompatibility, allowing them to be potentially used in the production of medical products.

\section{Conclusions and future prospects}

Torulene and torularhodin belong to a group of carotenoids synthesized only by yeast and fungi. These compounds are not currently produced on an industrial scale, however, they may be potentially used in many sectors of industry through to their valuable properties. First, these compounds can be used in the food industry and animal feed. Torulene and torularhodin could be used as antioxidants, as well as dyes, due to their rosy-red color. So far, the properties of these compounds have been only tested in rats and mice, so further research should required to determine their influence on the human body. It is also necessary to extend the toxicity studies and to determine the dose of ADI. The second direction concerns the use of torulene and torularhodin in the production of implanted medical products. Studies have shown that these compounds have strong anti-microbial properties, particularly against $E$. coli and $S$. aureus. Due to these properties, films containing these compounds can effectively protect against peri-implantation infections. The third direction concerns the use of torulene and torularhodin in the prevention of tumors, especially prostate cancer. The results are promising, but the scope of the research should be extended. In addition, another direction of studies should be aimed at the use of the waste microorganisms biomass, which may be used as feedstock additive for animals after extraction and removal of solvents. The use of waste biomass, rich in proteins and polysaccharides, would additionally improve the profitability of microbial carotenoid production.

Serious obstacle to the commercialization of production torulene and torularhodin is the low efficiency of biosynthesis. At present, profitable method of production has not been developed and high-yield producers of these compounds have not been obtained. The problem is also that the main producers of these compounds are yeasts that do not have GRAS status. Solutions to this problem can be found in modern genetic engineering techniques. If high-yield safe yeast mutants were to be obtained and the costs of producing torulene and torularhodin were low, these compounds would probably have been used in various industries.

\section{Authors' contributions}

AK, SB and IG contributed to literature search and analysis, and manuscript preparation, MK and JB prepared the tables and figures, and helped to draft the manuscript. All authors read and approved the final manuscript.

\section{Author details \\ ${ }^{1}$ Department of Biotechnology, Microbiology and Food Evaluation, Faculty of Food Sciences, Warsaw University of Life Sciences, Nowoursynowska 159C, 02-776 Warsaw, Poland. ${ }^{2}$ Department of Chemistry, Faculty of Food Sciences, Warsaw University of Life Sciences, Nowoursynowska 159C, 02-776 Warsaw, Poland.}

\section{Acknowledgements \\ Not applicable.}

\section{Competing interests}

The authors declare that they have no competing interests.

\section{Availability of data and materials}

Not applicable. The manuscript contains an overview of the literature and all data are available in it.

\section{Consent for publication}

Not applicable.

Ethics approval and consent to participate

Not applicable.

Funding

The work was financed by a statutory activity subsidy for the Faculty of Food Sciences of Warsaw University of Life Sciences.

\section{Publisher's Note}

Springer Nature remains neutral with regard to jurisdictional claims in published maps and institutional affiliations.

Received: 15 September 2017 Accepted: 17 March 2018

Published online: 27 March 2018

References

1. Schieber A, Weber F. Carotenoids. In: Carle R, Schweiggert R, editors. Handbook on natural pigments in food and beverages. London: Elsevier; 2016. p. 101-23.

2. Arathi BP, Sowmya PR, Vijay K, Baskaran V, Lakshminarayana R. Metabolomics of carotenoids: the challenges and prospects: a review. Trends Food Sci Technol. 2005;45:105-17.

3. Krinsky NI, Johnson EJ. Carotenoid actions and their relation to health and disease. Mol Aspects Med. 2005;26:459-516.

4. Brown L, Rimm EB, Seddon JM, Giovannucci EL, Chasan-Taber L, Spiegelman D, Willett WC, Hankinson SE. A prospective study of carotenoid intake and risk of cataract extraction in US men. Am J Clin Nutr. 1999;70:517-24

5. Beatty S, Nolan J, Kavanagh H, O'Donovan O. Macular pigment optical density and its relationship with serum and dietary levels of lutein and zeaxanthin. Arch Biochem Biophys. 2004;430:70-6.

6. Stahl W, Sies H. Carotenoids and flavonoids contribute to nutritional protection against skin damage from sunlight. Mol Biotechnol. 2007;37:26-30.

7. Fraser PF, Bramley PM. The biosynthesis and nutritional uses of carotenoids. Prog Lipid Res. 2004;43:228-65.

8. Cazzonelli Cl. Carotenoids in nature: insights from plants and beyond. Funct Plant Biol. 2001;38:833-47. 
9. Mata-Gómez LC, Montañez JC, Méndez-Zavala A, Aguilar CN. Biotechnological production of carotenoids by yeasts: an overview. Microb Cell Fact. 2014;13:1-11.

10. Bhosale P, Bernstein PS. Microbial xanthophylls. Appl Microbiol Biotechnol. 2005;68:445-55.

11. Herz S, Weber RS, Anke H, Mucci A, Davoli P. Intermediates in the oxidative pathway from torulene to torularhodin in the read yeasts Cystofilobasidium infirmominiatum and C. capitatum (Heterobasidiomycetes, Fungi). Phytochemistry. 2007;68:2503-11.

12. Sakaki H, Nakanishi T, Komemushi S, Namikawa K, Miki W. Torularhodin as a potent scavenger against peroxyl radicals isolated from a soil yeast, Rhodotorula glutinis. J Clin Biochem Nutr. 2001;30:1-10.

13. Sakaki H, Nochide H, Komemushi S, Miki W. Effect of active oxygen species on the productivity of torularhodin by Rhodotorula glutinis No. 21. J Biosci Bioeng. 2002;93:338-40.

14. Ungureanu C, Ferdes M. Evaluation of antioxidant and antimicrobial activities of torularhodin. Adv Sci Lett. 2012;5:1-4.

15. Maldonade IR, Rodriguez-Amaya DB, Scamparini ARP. Carotenoids of yeasts isolated from the Brazilian ecosystem. Food Chem. 2008:107:145-50.

16. Zoz L, Carvalho JC, Soccol VT, Casagrande TC, Cardoso L. Torularhodin and torulene: bioproduction, properties and prospective applications in food and cosmetics_a review. Braz Arch Biol Technol. 2015;58:278-88.

17. Goodwin TW. Biosynthesis of carotenoids. In: Goodwin TW, editor. The biochemistry of the carotenoids. Chapman and Hall: London; 1980. p. 33-76.

18. Peterson WJ, Bell TA, Etchells JL, Smart WWG. A procedure for demonstrating the presence of carotenoid pigments in yeasts. J Bacteriol. 1954;67:708-13.

19. Bonner J, Sandoval A, Tang YW, Zechmeister L. Changes in polyene synthesis induced by mutation in a red yeast (Rhodotorula rubra). Arch Biochem. 1946;10:113-23.

20. Madhour A, Anke H, Mucci A, Davoli P, Weber RS. Biosynthesis of the xanthophyll plectaniaxanthin as a stress response in the red yeast Dioszegia (Tremellales, Heterobasidiomycetes, Fungi). Phytochem. 2005;66:2617-26.

21. Villarreal P, Carrasco M, Barahona S, Alcaíno J, Cifuentes V, Baeza M. Tolerance to ultraviolet radiation of psychrotolerant yeasts and analysis of their carotenoid, mycosporine, and ergosterol content. Curr Microbiol. 2016;72:94-101.

22. Hausmann A, Sandmann G. A single five-step desaturase is involved in the carotenoid biosynthesis pathway to $\beta$-carotene and torulene in Neurospora crassa. Fung Gen Biol. 2000;30:147-53.

23. Buzzini P, Martini A. Production of carotenoids by strains of Rhodotorula glutinis cultured in raw materials of agro-industrial origin. Bioresour Technol. 1999:71:41-4.

24. Lee JJ, Chen L, Cao B, Chen WN. Engineering Rhodosporidium toruloides with a membrane transporter facilitates production and separation of carotenoids and lipids in a bi-phasic culture. Appl Microbiol Biotechnol. 2016;100:869-77.

25. Shi Q, Wang H, Du C, Zhang W, Qian H. Tentative identification of torulene cis/trans geometrical isomers isolated from Sporidiobolus pararoseus by high-performance liquid chromatography-diode array detection-mass spectrometry and preparation by column chromatography. Anal Sci. 2013;29:997-1002.

26. Li C, Zhang N, Li B, Xu Q, Song J, Wei N, Wang W, Zou H. Increased torulene accumulation in red yeast Sporidiobolus pararoseus NGR as stress response to high salt conditions. Food Chem. 2017;15:1041-7.

27. Cardoso LA, Jäckel S, Karp SG, Framboisier X, Chevalot I, Marc I. Improvement of Sporobolomyces ruberrimus carotenoids production by the use of raw glycerol. Bioresour Technol. 2016;200:374-9.

28. Davoli P, Weber RWS. Carotenoid pigments from the red mirror yeast Sporobolomyces roseus. Mycologist. 2002;16:102-8.

29. Dimitrova S, Pavlova K, Lukanov L, Korotkova E, Petrova E, Zagorchev P, Kuncheva M. Production of metabolites with antioxidant and emulsifying properties by Antarctic strain Sporobolomyces salmonicolor $\mathrm{AL}_{1}$. Appl Biochem Biotechnol. 2013;169:301-11.

30. Moliné M, Flores MR, Libkind D, Dieguéz MD, Farias ME, van Broock M. Photoprotection by carotenoid pigments in the yeast Rhodotorula mucilaginosa: the role of torularhodin. Photochem Photobiol Sci. 2010:9:1145-51.
31. Sakaki H, Nakanishi T, Tada A, Miki W, Komemushi S. Activation of torularhodin production by Rhodotorula glutinis using weak white light irradiation. J Biosci Bioeng. 2001:92:294-7.

32. Sperstad S, Lutnaes BF, Stormo SK, Liaaen-Jensen S, Landfald B. Torularhodin and torulene are the major contributors to the carotenoid pool of marine Rhodosporidium babjevae (Golubev). J Ind Microbiol Biotechnol. 2006;33:269-73.

33. Du C, Li Y, Guo Y, Han M, Zhang W, Qian H. Torularhodin, isolated from Sporidiobolus pararoseus, inhibits human prostate cancer LNCaP and PC-3 cell growth through Bcl-2/Bax mediated apoptosis and AR downregulation. RSC Adv. 2015;5(129):106387-95.

34. Razavi SH, Marc I. Effect of temperature and $\mathrm{pH}$ on the growth kinetics and carotenoid production by Sporobolomyces ruberrimus $\mathrm{H} 110$ using technical glycerol as carbon source. Iran J Chem Eng. 2006;25:59-64.

35. National Center for Biotechnology Information. 2018. https://www.ncbi. nlm.nih.gov. Accessed 22 Jan 2018.

36. Sakaki H, Nakanishi T, Satonaka KY, Miki W, Fujita T, Komemushi S. Properties of a high-torularhodin mutant of Rhodotorula g/utinis cultivated under oxidative stress. J Biosci Bioeng. 2000;89:203-5.

37. Frengova G, Simova E, Beshkova D. Use of whey ultrafiltrate as a substrate for production of carotenoids by the yeast Rhodotorula rubra. Appl Biochem Biotechnol. 2004;112:133-41.

38. Cheng YT, Yang CF. Using strain Rhodotorula mucilaginosa to produce carotenoids using food wastes. J Taiwan Inst Chem Eng. 2016;61:270-5.

39. Han M, Xu ZY, Du C, Qian H, Zhang WG. Effects of nitrogen on the lipid and carotenoid accumulation of oleaginous yeast Sporidiobolus pararoseus. Bioprocess Biosyst Eng. 2016;39:1425-33.

40. Buzzini $P$, Innocenti M, Turchetti B, Libkind D, Van Broock M, Mulinacci $\mathrm{N}$. Carotenoid profiles of yeasts belonging to the genera Rhodotorula, Rhodosporidium, Sporobolomyces, and Sporidiobolus. Can J Microbiol. 2007:53:1021-31.

41. Buzzini P, Martini A, Gaetani M, Turchetti B, Pagnoni UM, Davoli P. Optimization of carotenoid production by Rhodotorula graminis DBVPG 7021 as a function of trace element concentration by means of response surface analysis. Enzyme Microb Technol. 2005;36:687-92.

42. Tkáčová J, Furdíková K, Klempová T, Ďurčanská K, Čertík M. Screening of carotenoid-producing Rhodotorula strains isolated from natural sources. Acta Chim Slovaca. 2005:8:34-8.

43. Bhosale PB, Gadre RV. Production of $\beta$-carotene by a mutant of Rhodotorula glutinis. Appl Microbiol Biotechnol. 2001;55:423-7.

44. El-Banna AAER, El-Razek AMA, El-Mahdy AR. Isolation, identification and screening of carotenoid-producing strains of Rhodotorula glutinis. Food Nutr Sci. 2012;3:627-33.

45. Ungureanu C, Ferdes M, Chirvase AA. Torularhodin biosynthesis and extraction by yeast cells of Rhodotorula rubra. Rev Chim (Bucharest). 2012;63:316-8

46. Frengova G, Simova E, Beshkova D. Improvement of carotenoid-synthesizing yeast Rhodotorula rubra by chemical mutagenesis. Z Naturforsch C. 2004:59:99-103.

47. Varmira K, Habibi A, Moradi S, Bahramian E. Statistical optimization of airlift photobioreactor for high concentration production of torularhodin pigment. Biocatal Agric Biotechnol. 2016;8:197-203.

48. Irazusta V, Nieto-Penalver CG, Cabral ME, Amoroso MJ, de Figueroa LIC. Relationship among carotenoid production, copper bioremediation and oxidative stress in Rhodotorula mucilaginosa RCL-11. Process Biochem. 2013;48:803-9.

49. Moliné M, Libkind D, Diéguez MC, van Broock M. Photoprotective role of carotenoids in yeasts: response to UV-B of pigmented and naturallyoccurring albino strains. J Photochem Photobiol B. 2009;95:156-61.

50. Moliné M, Libkind D, Garcia V, Giraudo M. Production of pigments and photo-protective compounds by cold-adapted yeasts. In: Buzzini P, Margesin R, editors. Cold-adapted yeasts: biodiversity, adaptation strategies and biotechnological significance. Berlin: Springer; 2013. p. 193-224.

51. Simpson KL, Nakayama TOM, Chichester CO. Biosynthesis of yeast carotenoids. J Bacteriol. 1964;88:1688-94.

52. Hayman EP, Yokoyama H, Chichester CO, Simpson KL. Carotenoid biosynthesis in Rhodotorula glutinis. J Bacteriol. 1974;120:1339-43.

53. Kot AM, Błażejak S, Kurcz A, Gientka I, Kieliszek M. Rhodotorula glutinis - potential source of lipids, carotenoids, and enzymes for use in industries. Appl Microbiol Biotechnol. 2016;100:6103-17. 
54. Li C, Zhang N, Song J, Wei N, Li B, Zou H, Han X. A single desaturase gene from red yeast Sporidiobolus pararoseus is responsible for both four- and fivestep dehydrogenation of phytoene. Gene. 2016;590:169-76.

55. Mannazzu I, Landolfo S, da Silva TL, Buzzini P. Red yeasts and carotenoid production: outlining a future for non-conventional yeasts of biotechnological interest. World J Microbiol Biotechnol. 2015;31:1665-73.

56. Paul D, Magbanua Z, Arick M II, French T, Bridges SM, Burgess SC, Lawrence ML. Genome sequence of the oleaginous yeast Rhodotorula glutinis ATCC 204091. Genome Announc. 2014;2(1):e00046-14.

57. Firrincieli A, Otillar R, Salamov A, Schmutz J, Khan Z, Redman RS, Fleck ND, Lindquist E, Grigoriev IV, Doty SL. Genome sequence of the plant growth promoting endophytic yeast Rhodotorula graminis WP1. Front Microbiol. 2015:6:978

58. Gan HM, Thomas BN, Cavanaugh NT, Morales GH, Mayers AN, Savka MA Hudson AO. Whole genome sequencing of Rhodotorula mucilaginosa isolated from the chewing stick (Distemonanthus benthamianus): insights into Rhodotorula phylogeny, mitogenome dynamics and carotenoid biosynthesis. PeerJ. 2017;5:e4030. https://doi.org/10.7717/ peerj.4030.

59. $\mathrm{Hu}$ J, Ji L. Draft genome sequences of Rhodosporidium toruloides strains ATCC 10788 and ATCC 10657 with compatible mating types. Genome Announc. 2016;4:e00098-116.

60. Kumar S, Kushwaha H, Bachhawat AK, Raghava GP, Ganesan K. Genome sequence of the oleaginous red yeast Rhodosporidium toruloides MTCC 457. Eukaryot Cell. 2012;11:1083-4.

61. Morin N, Calcas X, Devillers H, Durrens P, Sherman DJ, Nicaud JM, Neuvéglise C. Draft genome sequence of Rhodosporidium toruloides CECT1137, an oleaginous yeast of biotechnological interest. Genome Announc. 2014;2:e00641-14

62. Sambles C, Middelhaufe S, Soanes D, Kolak D, Lux T, Moore K, Matoušková P, Parker D, Lee R, Love J, Aves SJ. Genome sequence of the oleaginous yeast Rhodotorula toruloides strain CGMCC 2.1609. Genomics Data. 2017;13:1-2. https://doi.org/10.1016/j.gdata.2017.05.009.

63. Zhu Z, Zhang S, Liu H, Shen H, Lin X, Yang F, Zhou JY, Jin G, Ye M, Zou $\mathrm{H}$, Zhao ZK. A multi-omic map of the lipid-producing yeast Rhodosporidium toruloides. Nat Commun. 2012;2012(3):1112. https://doi. org/10.1038/ncomms2112.

64. Landolfo S, laniri G, Camiolo S, Porceddu A, Mulas G, Chessa R, Zara G, Mannazzu I. CAR gene cluster and transcript levels of carotenogenic genes in Rhodotorula mucilaginosa. Microbiology. 2018;164:78-87.

65. Wang Q, Liu D, Yang Q, Wang P. Enhancing carotenoid production in Rhodotorula mucilaginosa KC8 by combining mutation and metabolic engineering. Ann Microbiol. 2017;67:425-31.

66. Aksu Z, Eren AT. 2005: carotenoids production by the yeast Rhodotorula mucilaginosa: use of agricultural wastes as a carbon source. Process Biochem. 2005:40:2985-91.

67. El-Banna AA, El-Razek AAM, El-Mahdy AR. Some factors affecting the production of carotenoids by Rhodotorula glutinis var. glutinis. Food Nutr Sci. 2012;3:64-71

68. Freitas C, Parreira TM, Roseiro J, Reis A, da Silva TL. Selecting low-cost carbon sources for carotenoid and lipid production by the pink yeast Rhodosporidium toruloides NCYC 921 using flow cytometry. Bioresour Technol. 2014;158:355-9.

69. Voaides C, Dima R. Effect of carbon source on carotenoid production by Rhodotorula sp. Archiva Zootechnica. 2011;14:75-83.

70. Frengova Gl, Beshkova DM. Carotenoids from Rhodotorula and Phaffia: yeasts of biotechnological importance. J Ind Microbiol Biotechnol. 2009;36:163-80.

71. Simova ED, Frengova Gl, Beshkova DM. Effect of aeration on the production of carotenoid pigments by Rhodotorula rubra-lactobacillus casei subsp. casei co-cultures in whey ultrafiltrate. Z Naturforsch C. 2003;58:225-9.

72. Frengova Gl, Simova ED, Beshkova DM. Effect of temperature changes on the production of yeast pigments co-cultivated with lacto-acid bacteria in whey ultrafiltrate. Biotechnol Lett. 1995;17:1001-6.

73. Bhosale PB. Environmental and cultural stimulants in the production of carotenoids from microorganisms. Appl Microbiol Biotechnol. 2004:63:351-61.

74. Sigler K, Chaloupka J, Brozmanova J, Stadler N, Höfer M. Oxidative stress in microorganisms. Folia Microbiol. 1999:1999(44):587-624.
75. Marova I, Carnecka M, Halienova A Certik M, Dvorakova T, Haronikova A. Use of several waste substrates for carotenoid-rich yeast biomass production. J Environ Manag. 2012:95:338-42.

76. Zhang Z, Zhang X, Tan T. Lipid and carotenoid production by Rhodotorula glutinis under irradiation/high-temperature and dark/lowtemperature cultivation. Bioresour Technol. 2014;157:149-53.

77. Mihalcea A, Onu A, Tucureanu C, Ungureanu C, Raileanu S, Salageanu A, Muntean O. Extraction of torularhodin from Rhodotorula rubra yeast using sunflower oil. Rev Chim (Bucharest). 2015:66:1692-5.

78. Valduga E, Valerio A, Tatsch PO, Treichel H, Furigo AJ, Di Luccio M. Assessment of cell disruption and carotenoids extraction from Sporidiobolus salmonicolor (CBS 2636). Food Bioprocess Technol. 2009;2:234-8.

79. Monks LM, Rigo A, Mazutti MA, Vladimir Oliveira J, Valduga E. Use of chemical, enzymatic and ultrasound-assisted methods for cell disruption to obtain carotenoids. Biocatal Agric Biotechnol. 2013;2:165-9.

80. Cabral SMM, Cence K, Zeni J, Tsai SM, Durrer A, Foltran LL, Toniazzo G, Valduga $\mathrm{E}$, Treichel $\mathrm{H}$. Carotenoids production from a newly isolated Sporidiobolus pararoseus strain by submerged fermentation. Eur Food Res Technol. 2011;233:159-66.

81. Park PK, Kim EY, Chu KH. Chemical disruption of yeast cells for the isolation of carotenoid pigments. Sep Purif Technol. 2007;53:148-52.

82. Park PK, Cho DH, Kim EY, Chu KH. Optimization of carotenoid production by Rhodotorula glutinis using statistical experimental design. World J Microbiol Biotechnol. 2005:21:429-34.

83. Malisorn C, Suntonsuk W. Improved $\beta$-carotene production of Rhodotorula glutinis in fermented radish brine by continuous cultivation. Biochem Eng J. 2009;43:27-32.

84. Ferrao M, Garg S. Shake flask optimization of $\beta$-carotene production in Rhodotorula graminis RC04. Afr J Biotechnol. 2012;11:11431-7.

85. Cutzu R, Coi A, Rosso F, Bardi L, Ciani M, Budroni M, Zara G, Zara S, Mannazzu I. From crude glycerol to carotenoids by using a Rhodotorula glutinis mutant. World J Microbiol Biotechnol. 2013;29:1009-17.

86. Panesar R, Patil SD, Panesar PS. Standardization of medium components and process parameters for biopigment production using Rhodotorula glutinis. Intl J Food Ferment Technol. 2013;3:149-56.

87. Ungureanu C, Marchal L, Chirvase AA, Foucault A. Centrifugal partition extraction, a new method for direct metabolites recovery from culture broth: case study of torularhodin recovery from Rhodotorula rubra. Bioresour Technol. 2013;132:406-9.

88. Latha BV, Jeevaratanm K. Purification and characterization of the pigments from Rhodotorula glutinis DFR-PDY isolated from natural source. Glob J Biotechnol Biochem. 2010;5:166-74.

89. Ungureanu C, Ferdes M, Chirvase AA, Mocanu E. Method for torularhodin separation and analysis in the yeast Rhodotorula rubra aerobically cultivated in lab bioreactor. In: Icheap-10: 10th Int. Conf. on Chemical and Process Engineering, Pts 1-3. S. Pierucci 24. 2011. p. 943-48.

90. Razavi SH, Blanchard F, Marc I. UV-HPLC/APCI-MS method for separation and identification of the carotenoids produced by Sporobolomyces ruberrimus H110. Iran J Chem Chem Eng. 2006:25:1-10.

91. Kim BK, Park PK, Chae HJ, Kim EY. Effect of phenol on $\beta$-carotene content in total carotenoids production in cultivation of Rhodotorula glutinis. Korean J Chem Eng. 2004;21:689-92.

92. Freitas C, Nobre B, Gouveia L, Roseiro J, Reis A, Lopes da Silva T. New atline flow cytometric protocols for determining carotenoid content and cell viability during Rhodosporidium toruloides NCYC 921 batch growth. Process Biochem. 2014:49:554-62.

93. Weber RWS, Anke H, Davoli P. Simple method fort the extraction and reversed-phase high-performance liquid chromatographic analysis of carotenoid pigments from red yeast (Basidiomycota, Fungi). J Chromatogr A. 2007:1145:118-22.

94. Braunwald T, Schwemmlein L, Graeff-Hönninger S, French WT, Hernandez R, Holmes WE, Claupein W. Effect of different C/N ratios on carotenoid and lipid production by Rhodotorula glutinis. Appl Microbiol Biotechnol. 2013:97:6581-8.

95. Perrier V, Dubreucq E, Galzy P. Fatty acid and carotenoid composition of Rhodotorula strains. Arch Microbiol. 1995;164:173-9.

96. Malisorn C, Suntornsuk W. Optimization of $\beta$-carotene production by Rhodotorula glutinis DM28 in fermented radish brine. Bioresour Technol. 2008:99.2281-7. 
97. Libkind D, van Broock M. Biomass and carotenoid pigment production by Patagonian native yeasts. World J Microbiol Biotechnol. 2006;22:687-92

98. Nasrabadi MRN, Razavi SH. Optimization of $\beta$-carotene production by a mutant of the lactose-positive yeast Rhodotorula acheniorum from whey ultrafiltrate. Food Sci Biotechnol. 2011;20:445-54.

99. Yimyoo T, Yongmanitchai W, Limtong S. Carotenoid production by Rhodosporidium paludigenum DMKU3-LPK4 using glycerol as the carbon source. Kasetsart J (Nat Sci). 2011:45:90-100.

100. Minguez-Mosquera MI, Hornero-Mendez D. Separation and quantification of the carotenoid pigments in red peppers (Capsicum annuum L.) paprika, and oleoresin by reversed-phase HPLC. J Agric Food Chem. 1993:41:1616-20. https://doi.org/10.1021/jf00034a018.

101. Heidlas J, Cully J, Wiesmuller J, Vollbrecht HR. Process for the extraction of natural carotenoid dyes. Patent US5789647 A. 1995.

102. Heidlas J, Huber G, Cully J, Kohlrausch U. Process for the extraction of carotenes from natural sources. Patent US 5714658 A. 1996.

103. Zelkha M, Sedlov T. Carotenoid extraction process. Patent US 6797303 B2. 2004.

104. Butnariu M. Methods of analysis (extraction, separation, identification and quantification) of carotenoids from natural products. J Ecosys Ecogr. 2016;6:193.

105. Yu L, Wang H, Lu M, He M, He F. Method for preparing and extracting from microbial thalli. Patent CN 102732049 B. 2012

106. Wiesmann U, Binder H. Biomass separation from liquids by sedimentation and centrifugation. Adv Biochem Eng/Biotechnol. 1982;24:119-71.

107. Kaiser P, Surmann P, Vallentin G, Fuhrmann H. A small-scale method for quantitation of carotenoids in bacteria and yeasts. J Microbiol Methods. 2007;70:142-9.

108. Swaminathan S, Madavalappil K.P. Isolation and purification of carotenoids from marigold flowers. Patent EP1877371. 2009.

109. Leigh MLS, Leigh S, Hoogevest Peter Van PH. Direct dissolution of carotenoids in edible oils and fats. Patent EP2266419 A1. 2010
110. Latha BV, Jeevaratanm K. Thirteen-week oral toxicity study of carotenoid pigment from Rhodotorula glutinis DFR-PDY in rats. Indian J Exp Biol. 2012;50:645-51.

111. Bhosale P, Motiwale L, Ingle AD, Gadre RV, Rao KVK. Protective effect of Rhodotorula glutinis NCIM 3353 on the development of hepatic preneoplastic lesions. Curr Sci. 2002;83:303-8.

112. Du C, Li Y, Guo Y, Han M, Zhang W, Qian H. The suppression of torulene and torularhodin treatment on the growth of $\mathrm{PC}-3$ xenograft prostate tumors. Biochem Biophys Res Commun. 2016:469:1146-52

113. Du C, Guo Y, Cheng Y, Han M, Zhang W, Qian H. Anti-cancer effects of torulene, isolated from Sporidiobolus pararoseus, on human prostate cancer LNCaP and PC-3 cells via a mitochondrial signal pathway and the down-regulation of AR expression. RSC Adv. 2017;7:2466-74.

114. Wu JL, Wang WY, Cheng YL, Du C, Qian H. Neuroprotective effects of torularhodin against $\mathrm{H}_{2} \mathrm{O}_{2}$-induced oxidative injury and apoptosis in PC12 cells. Pharmazie. 2015;70:17-23.

115. Keceli TM, Erginkaya Z, Turkkan E, Kaya U. Antioxidant and antibacterial effects of carotenoids extracted from Rhodotorula glutinis strains. Asian J Chem. 2013;25:42-6.

116. Manimala MRA, Murugesan R. In vitro antioxidant and antimicrobial activity of carotenoid pigment extracted from Sporobolomyces sp. isolated from natural source. J Appl Nat Sci. 2014;6:649-53.

117. Dumitriu C, Ungureanu C, Popescu S, Tofan V, Popescu M, Pirvu C. Ti surface modification with a natural antioxidant and antimicrobial agent. Surf Coat Technol. 2015;276:175-85.

118. Ungureanu C, Popescu S, Purcel G, Tofan V, Popescu M, Sălăgeanu A, Pîrvu C. Improved antibacterial behavior of titanium surface with torularhodin-polypyrrole film. Mater Sci Eng C. 2014;42:726-33.

119. Ungureanu C, Dumitriu C, Popescu S, Enculescu M, Tofan V, Popescu $\mathrm{M}$, Pirvua $\mathrm{C}$. Enhancing antimicrobial activity of $\mathrm{TiO}_{2} / \mathrm{Ti}$ by torularhodin bioinspired surface modification. Bioelectrochemistry. 2016;107:14-24.

\section{Submit your next manuscript to BioMed Central and we will help you at every step:}

- We accept pre-submission inquiries

- Our selector tool helps you to find the most relevant journal

- We provide round the clock customer support

- Convenient online submission

- Thorough peer review

- Inclusion in PubMed and all major indexing services

- Maximum visibility for your research

Submit your manuscript at www.biomedcentral.com/submit
O Biomed Central 